\title{
The therapeutic plan implementation in patients discharged from the hospital after myocardial infarction
}

Key words: adherence, myocardial infarction; $A C E I$, P2Y $_{12}$ receptor inhibitors, statins Med Res J 2021; 6 (2): 79-82

According to the European Society of Cardiology guidelines dual antiplatelet therapy (DAPT) for 12 months, angiotensin-converting enzyme inhibitor (ACEI) or angiotensin receptor blocker (ARB), beta-blocker and statin [1] are recommended in patients after myocardial infarction (MI). Adherence to this treatment determines the achievement of therapeutic targets [2-8]. Previous studies have shown that patients after MI often do not adhere to the treatment plan. Discontinuation of the recommended post-MI therapy predisposes to serious thrombotic events, particularly MI, in-stent thrombosis, stroke and death [9-14]. The knowledge regarding the level and determinants of adherence to treatment recommendations in post-MI patients enables proper care and education planning for this population.

The series of recent publications reporting results of a single centre, observational, cohort clinical trial with 1-year follow-up, was intended to reflect 'real world' practice [15-18]. All study participants received in-hospital educational and motivational verbal interventions on ischemic heart disease, focusing on its symptoms and management supported by an educational brochure entitled "Myocardial infarction" that was handed out at the beginning of hospitalization. The first educational visit was carried out within the first two days after admission to the hospital. The visit included an assessment of patient knowledge of the disease, its symptoms, and prevention (20 standardized questions). Throughout the entire hospital stay, patients had an opportunity to ask questions and obtain comprehensive answers. The educational and motivational visits were conducted by trained educational nurses.

The readiness for discharge from the hospital was assessed using a validated questionnaire Readiness for Hospital Discharge after Myocardial Infarction Scale (RHD-MIS) [19, 20]. The RHDS-MIS consists of 23 questions included in three subscales assessing subjective (assessed by the patient) and objective (assessed by medical personnel) knowledge about the disease and patient expectations. Additionally, the questionnaire contains non-scored questions regarding the patient's opinion on the readiness for discharge.

The analysis of medication discontinuation was performed based on prescription filling data provided by the National Health Fund (NHF) for reimbursed drugs: ACEI (ramipril, perindopril) $\mathrm{P}_{2 Y_{12}}$ receptor inhibitor (clopidogrel) and statin (atorvastatin, simvastatin, rosuvastatin). The NHF is the only institution in Poland that covers the costs of hospitalization, outpatient treatment and prescribed medications. Drugs non-reimbursed by the NHF were not included in the analysis. All study participants patients received appropriate prescriptions (including $\mathrm{ACEI}, \mathrm{P}_{2} \mathrm{Y}_{12}$ receptor inhibitor and statin) at discharge from the hospital. Two hundred fifty-two patients were enrolled on the study. The final analysis was conducted for 225 participants $(73.3 \%$ men, $26.7 \%$ women) aged 30-91 years (mean age $62.9 \pm 11.9$ years), for whom data were obtained from the National Health Fund.

According to the authors' best knowledge, this research [15-18] is the first one to comprehensively 
analyse the level of adherence to medication and its determinants as well as the variability of these determinants during the follow-up after hospital discharge.

The mean adherence level during 1-year of follow-up for all three groups of medications (ACEls, $\mathrm{P}_{2} \mathrm{Y}_{12}$ receptor inhibitors and statins) was $64.1 \pm 24.5 \%$, with a value of $67.2 \pm 31.8 \%$ for ACEI, $61.6 \pm 34.2 \%$ for P2Y12 receptor inhibitors, and $64.4 \pm 32.1 \%$ for statins. Over time, a gradual decline in adherence was observed for all groups of medications. Sufficient adherence for all medication groups was found only in $29.4 \%$ of patients throughout the whole follow-up period [15-18]. These findings are in line with those obtained by Naderi et al. [2] in a meta-analysis of 20 studies evaluating 7 groups of drugs showing a mean adherence level of $57.0 \%$ and its decline over consecutive quarters of follow-up. Similar findings were reported also in other publications [11-14].

The multivariate analysis defined determinants of medication adherence: age under 65 years in the first quarter of follow-up for ACEI, P2Y12 receptor inhibitor and statin; prior CABG in the 1st quarter of follow up for ACEI and P2Y12 receptor inhibitor; level of education and place of residence for P2Y12 receptor inhibitor in the 1st quarter of follow-up; economic status for all assessed drugs in the 2nd quarter; marital status for ACEI in the 1st quarter of follow-up; arterial hypertension for ACEl in the 1st quarter of follow-up [15-18]. Identifying the factors responsible for the decline in adherence in the sequential quarters helps better understand the mechanisms governing this phenomenon and apply targeted corrective interventions. Additional educational and motivational efforts should be directed to elderly, less educated, living alone patients and those after CABG in order to increase the likelihood of implementation of prescribed medication after discharge from the hospital. Maintenance of medication during long term treatment requires special support in rural residents and patients with lower economic status [15-18].

The therapy discontinuation remains a challenge for therapeutic teams. Elimination of this phenomenon might largely improve the clinical and economical outcomes of treatment $[3,8,16]$.

The highest likelihood of therapy discontinuation, including long-term discontinuation (> 30 days) and permanent therapy cessation was found for statins and the lowest for ACEls. It was found that patients are most prone to discontinue therapy between the 2nd and 3rd quarter of follow-up. In contrast to the permanent cessation of therapy, a significant increase in the incidence of temporary therapy discontinuation was already seen in the 1st quarter of follow-up [15-18].

Multivariate logistic regression analysis identified occupational activity and a prior $\mathrm{Ml}$ as independent predictors of lack of post-discharge therapy initiation with P2Y12 receptor inhibitors. The research found no predictors of lack of post-discharge therapy initiation with other medications either when analysed individually or together. Multivariate analysis indicated age above 65 years and prior revascularization as independent predictors of therapy discontinuation but failed to identify independent predictors of the permanent cessation of therapy with any of the medications as well as the temporary discontinuation and permanent cessation of treatment with all three medications together [15-18].

Preparation for discharge, including education in the field of secondary prevention after a MI, is a current standard of care, however, not always meeting the patient's expectations [21-27].

The assessment of readiness for discharge was based on the RHD-MIS. The analysis of adherence to treatment in relation to the results achieved in RHD MIS did not provide unequivocal results both in terms of the overall result and the results in individual subscales. This applies to individual drug groups tested separately and to all groups together. Significant differences noted in individual quarters for individual drugs may, contrary to expectations, suggest worse adherence in patients who were better prepared for discharge from the hospital [15-18]. These surprising results require further in-depth research to explain this phenomenon. According to the previously published studies, better adherence to treatment should be expected in patients with a higher level of readiness for discharge. The study confirms that patient education should continue after discharge from the hospital [26-36].

The patients with a high expectation score had longer treatment interruptions only for the P2Y12 receptor inhibitor. No relations between medication adherence and the level of expectations were found in the first two quarters, while for the last two-quarters of follow-up, however, an inverse relationship between the level of expectations and adherence was shown. When related to the levels of expectations (high vs medium vs low), adherence for ACEl in the $4^{\text {th }}$ quarter of follow-up was $39 \pm 31 \%$ vs. $58 \pm 43 \%$ vs. $57 \pm 43 \%$ ( $p=0.0099$; $R=-0,16 ; p=0.0187)$. Similarly, for P2Y12 inhibitor the numbers were $37 \pm 41 \%$ vs. $53 \pm 43 \%$ vs. $55 \pm 41 \%$ $(p=0.0282 ; R=-0,15 ; p=0.0438)$. No differences, however, were found for statins [15-18].

The observed relation of expectations and adherence might indicate a mismatch between the educational contents and patient expectations. The study protocol, however, did not include additional educational initiatives to be delivered to fulfil patient individual expectations after the provision of the standard education intervention. The identification of patient expectations might allow further personalization of educational and motivational programmes [15-18].

Several limitations of the research reported in the series of publications should be considered. Medications non-reimbursed by the National Health Fund 
were excluded from the analysis. The authors analysed a limited number of factors as potential determinants of therapy discontinuation. Moreover, the authors do not have patients' reports concerning the reasons for therapy discontinuation. On the other hand, the strengths of this research are comprehensiveness and the homogeneity of the study population.

The reported research enabled making several important observations.

The vast majority of post-MI patients discontinue, either temporarily or permanently, one of the essential medications within one year following MI. Adherence to pharmacotherapy decreases over time after MI. Several socioeconomic and clinical factors have been identified to affect medication adherence over time. The readiness for discharge from the hospital assessed with the RHDMIS does not clearly affect the implementation of the therapeutic plan in the long-term follow-up in patients after MI. Data suggesting a negative impact of some aspects of readiness for discharge on adherence to treatment require further, in-depth research.

\section{References}

1. Ibanez B, James S, Agewall S, et al. ESC Scientific Document Group. 2017 ESC Guidelines for the management of acute myocardial infarction in patients presenting with ST-segment elevation: The Task Force for the management of acute myocardial infarction in patients presenting with ST-segment elevation of the European Society of Cardiology (ESC). Eur Heart J. 2018; 39(2): 119-177, doi: 10.1093/eurheartj/ehx393, indexed in Pubmed: 28886621.

2. Naderi SH, Bestwick JP, Wald DS. Adherence to drugs that prevent cardiovascular disease: meta-analysis on 376,162 patients. Am J Med. 2012; 125(9): 882-887.e1, doi: 10.1016/j.amjmed.2011.12.013, indexed in Pubmed: 22748400.

3. Spertus JA, Kettelkamp R, Vance C, et al. Prevalence, predictors and outcomes of premature discontinuation of thienopyridine therapy after drug-eluting stent placement: results from the PREMIER registry. Circulation. 2006; 113(24): 2803-2809, doi: 10.1161/CIRCULATIONAHA.106.618066, indexed in Pubmed: 16769908.

4. Ho PM, Spertus JA, Masoudi FA, et al. Impact of medication therapy discontinuation on mortality after myocardial infarction. Arch Intern Med. 2006; 166(17): 1842-1847, doi: 10.1001/archinte.166.17.1842, indexed in Pubmed: 17000940.

5. Tuppin P, Neumann A, Danchin N, et al. Evidence-based pharmacotherapy after myocardial infarction in France: adherence-associated factors and relationship with 30-month mortality and rehospitalization. Arch Cardiovasc Dis. 2010; 103(6-7): 363-375, doi: 10.1016/j. acvd.2010.05.003, indexed in Pubmed: 20800800.

6. Chen HY, Saczynski JS, Lapane KL, et al. Adherence to evidence-based secondary prevention pharmacotherapy in patients after an acute coronary syndrome: A systematic review. Heart Lung. 2015; 44(4): 299-308, doi: 10.1016/j.hrtlng.2015.02.004, indexed in Pubmed: 25766041.

7. Kubica A, Obońska K, Kasprzak M, et al. Prediction of high risk of non-adherence to antiplatelet treatment. Kardiol Pol. 2016; 74(1): 61-67, doi: 10.5603/KP.a2015.0117, indexed in Pubmed: 26101025.

8. Kassab Y, Hassan Y, Abd Aziz N, et al. Patients' adherence to secondary prevention pharmacotherapy after acute coronary syndromes. Int $J$ Clin Pharm. 2013; 35(2): 275-280, doi: 10.1007/s11096-012-9735-y, indexed in Pubmed: 23283596.

9. Kubica A, Kasprzak M, Obońska K, et al. Discrepancies in assessment of adherence to antiplatelet treatment after myocardial infarction. Pharmacology. 2015; 95(1-2): 50-58, doi: 10.1159/000371392, indexed in Pubmed: 25592409.

10. Kubica A, Kosobucka A, Michalski P, et al. Self-reported questionnaires for assessment adherence to treatment in patients with cardiovascu- lar diseases. Medical Research Journal. 2018; 2(4): 115-122, doi: 10.5603/mrj.2017.0015.

11. Choudhry NK, Fischer MA, Avorn J, et al. The implications of therapeutic complexity on adherence to cardiovascular medications. Arch Intern Med. 2011; 171(9): 814-822, doi: 10.1001/archinternmed.2010.495, indexed in Pubmed: 21555659.

12. Thim T, Johansen MB, Chisholm GE, et al. Clopidogrel discontinuation within the first year after coronary drug-eluting stent implantation: an observational study. BMC Cardiovasc Disord. 2014; 14: 100, doi: 10.1186/1471-2261-14-100, indexed in Pubmed: 25125079.

13. Jánosi $A$, Ofner $P$ Kiss $Z$, et al. Adherence to medication after myocardial infarction and its impact on outcome: a registry-based analysis from the Hungarian Myocardial Infarction Registry. Orv Hetil. 2017; 158(27): 1051-1057, doi: 10.1556/650.2017.30795, indexed in Pubmed: 28670984

14. Korhonen MJ, Robinson JG, Annis IE, et al. Adherence Tradeoff to Multiple Preventive Therapies and All-Cause Mortality After Acute Myocardial Infarction. J Am Coll Cardiol. 2017; 70(13): 1543-1554, doi: 10.1016/j.jacc.2017.07.783, indexed in Pubmed: 28935030.

15. Pietrzykowski Ł, Kasprzak M, Michalski P, et al. Medication adherence and its determinants in patients after myocardial infarction. Sci Rep. 2020; 10(1): 12028, doi: 10.1038/s41598-020-68915-1, indexed in Pubmed: 32694522

16. Kosobucka A, Pietrzykowski $Ł$, Michalski $P$, et al. Impact of readiness for discharge from the hospital on the implementation of the therapeutic plan. Medical Research Journal. 2020; 5(4): 256-264, doi: 10.5603/mri.a2020.0047.

17. Pietrzykowski $\measuredangle$, Kasprzak M, Michalski P, et al. Therapy Discontinuation after Myocardial Infarction. J Clin Med. 2020; 9(12), doi: 10.3390/jcm9124109, indexed in Pubmed: 33352811.

18. Pietrzykowski $\measuredangle$, Kasprzak M, Michalski $P$, et al. The influence of patient expectations on adherence to treatment regimen after myocardial infarction, Patient Educ Couns, doi: https://doi.org/10.1016/j. pec.2021.05.030

19. Buszko K, Kosobucka A, Michalski P, et al. The readiness for hospital discharge of patients after acute myocardial infarction: a new self-reported questionnaire. Medical Research Journal. 2017; 2(1): 20-28, doi: 10.5603/mrj.2017.0004.

20. Kosobucka A, Kasprzak M, Michalski P, et al. Relation of the Readiness for Hospital Discharge after Myocardial Infarction Scale to socio-demographic and clinical factors. An observational study. Medical Research Journal. 2018; 3(1): 32-37, doi: 10.5603/mrj.2018.0006.

21. Smith J, Liles C. Information needs before hospital discharge of myocardial infarction patients: a comparative, descriptive study. J Clin Nurs. 2007; 16(4): 662-671, doi: 10.1111/j.1365-2702.2006.01689.x, indexed in Pubmed: 17402947

22. Kubica A, Kasprzak M, Obońska K, et al. Impact of health education on adherence to clopidogrel and clinical effectiveness of antiplatelet treatment in patients after myocardial infarction. Medical Research Journal. 2016; 3(4): 154-159, doi: 10.5603/fmc.2015.0010.

23. Wiles R, Kinmonth AL. Patients' understandings of heart attack: implications for prevention of recurrence. Patient Education and Counseling 2001: 44(2): 161-169, doi: 10.1016/s0738-3991(00)00187-7.

24. Kubica A, Adamski P, Baczkowska A, et al. The rationale for Multilevel Educational and Motivational Intervention in Patients after Myocardial Infarction (MEDMOTION) project is to support multicentre randomized clinical trial Evaluating Safety and Efficacy of Two Ticagrelor-based De-escalation Antiplatelet Strategies in Acute Coronary Syndrome (ELECTRA - SIRIO 2). Medical Research Journal. 2020; 5(4): 244-249, doi: $10.5603 / \mathrm{mrj}$.a2020.0043

25. Crowley MJ, Zullig LL, Shah BR, et al. Medication non-adherence after myocardial infarction: an exploration of modifying factors. J Gen Intern Med. 2015; 30(1): 83-90, doi: 10.1007/s11606-014-3072-x, indexed in Pubmed: 25361685.

26. Michalski P, Kasprzak M, Siedlaczek M, et al. The impact of knowledge and effectiveness of educational intervention on readiness for hospital discharge and adherence to therapeutic recommendations in patients with acute coronary syndrome. Medical Research Journal. 2020, doi: 10.5603/mrj.a2020.0023.

27. Kubica A, Gruchała M, Jaguszewski M, et al. Adherence to treatment - a pivotal issue in long-term treatment of patients with cardiovascular diseases. An expert standpoint. Medical Research Journal. 2018; 2(4): 123-127, doi: 10.5603/mri.2017.0016.

28. Kubica J, Adamski P, Buszko K, et al. Rationale and Design of the Effectiveness of LowEr maintenanCe dose of TicagRelor early After myocardial infarction (ELECTRA) pilot study. Eur Heart J Cardiovasc Pharmacother. 2018; 4(3): 152-157, doi: 10.1093/ehjcvp/pvx032, indexed in Pubmed: 29040445. 
29. Vermeire $E$, Hearnshaw $H$, Van Royen $P$, et al. Patient adherence to treatment: three decades of research. A comprehensive review. J Clin Pharm Ther. 2001; 26(5): 331-342, doi: 10.1046/j.1365 2710.2001.00363.x, indexed in Pubmed: 11679023.

30. Polack J, Jorgenson D, Robertson P. Evaluation of different methods of providing medication-related education to patients following myocardial infarction. Canadian Pharmacists Journal. 2008; 141(4): 241-247, doi: 10.3821/1913-701x(2008)141[241:eodmop]2.0.co;2.

31. Kosobucka A, Michalski P, Pietrzykowski $\measuredangle$, et al. Adherence to treatment assessed with the Adherence in Chronic Diseases Scale in patients after myocardial infarction. Patient Prefer Adherence. 2018; 12: 333-340, doi: 10.2147/PPA.S150435, indexed in Pubmed: 29551891.

32. Kubica A, Kosobucka A, Michalski P, et al. The Adherence in Chronic Diseases Scale - a new tool to monitor implementation of a treatment plan. Folia Cardiologica 2017;12:19-26, DOI: 10. 5603/FC. ; 2016 0000, doi: 10.5603/FC 2016.0000.
33. Kubica A, Kochman W, Bogdan M, et al. The influence of undergone percutaneous coronary interventions, and earlier hospitalizations with myocardial infarction on the level of knowledge and the effectiveness of health education in patients with myocardial infarction. Advances in Interventional Cardiology. 2009; 5: 25-30.

34. DiMatteo MR. Variations in patients' adherence to medical recommendations: a quantitative review of 50 years of research. Med Care. 2004; 42(3): 200-209, doi: 10.1097/01.mlr.0000114908.90348.f9, indexed in Pubmed: 15076819.

35. Kubica A, Obońska K, Fabiszak T, et al. Adherence to antiplatelet treatment with $\mathrm{P} 2 \mathrm{Y} 12$ receptor inhibitors. Is there anything we can do to improve it? A systematic review of randomized trials. Curr Med Res Opin. 2016; 32(8): 1441-1451, doi: 10.1080/03007995.2016.1182901, indexed in Pubmed: 27112628.

36. Kubica A, Kasprzak M, Siller-Matula J, et al. Time-related changes in determinants of antiplatelet effect of clopidogrel in patients after myocardial infarction. Eur J Pharmacol. 2014; 742: 47-54, doi: 10.1016/j. ejphar.2014.08.009, indexed in Pubmed: 25199965. 